\title{
Obesity, Cytokines and Cognition across the Lifespan among People Living with HIV
}

\author{
María José Míguez ${ }^{1 *}$, Diego Bueno ${ }^{1}$, Caroline Perez ${ }^{1}$, Luis A Espinoza², Mayra E Vargas ${ }^{1}$, Clery Quiros ${ }^{1}$ and Ronald Cohen ${ }^{3}$ \\ ${ }^{1}$ Health Behavior and Policy Initiative, School of Integrated Science and Humanity, Florida International University, Miami, USA \\ ${ }^{2}$ Division of Infectious Diseases, Department of Medicine, University of Miami, Miami, USA
}

${ }^{3}$ University of Florida Institute on Aging, Gainesville, USA

\begin{abstract}
Background/objective: Neurocognitive Impairment $(\mathrm{NCl})$ remains prevalent among people living with HIV (PLWH/AIDS), and may be exacerbated by body core changes. Waist circumference, a metabolic syndrome (MetSy) criterion, is not routinely measured, yet could be particularly useful when considering that both antiretroviral therapy (ART) and Hazardous alcohol use (HAU) have been associated with central fat accumulation. The purpose of this work was to examine the longitudinal associations between body mass index (BMI), waist circumference (WC), and cognitive performance in PLWH/AIDS, and to explore their modifications by age.
\end{abstract}

Methods: Using a prospective cohort study, we obtained participants' anthropometrics, along with a comprehensive cognitive assessment over one year. Subjects were classified as overweight if BMI was $25-29.9 \mathrm{~kg} / \mathrm{m}^{2}$, and obese if BMI was $\geq 30 \mathrm{~kg} / \mathrm{m}^{2}$. Central obesity was defined as a waist $>35$ inches for females and $>40$ inches for males. Neurocognitive Impairment was defined using individual and global deficit corrected scores.

Results/conclusion: A sizable proportion of participants met the National Institutes of Health definition of overweight $\left(B M I=25-29.9 \mathrm{~kg} / \mathrm{m}^{2} ; 26 \%\right)$ and obese $\left(\mathrm{BMI} \geq 30 \mathrm{~kg} / \mathrm{m}^{2} ; 35 \%\right)$. Central obesity was present in more than half of the population $(52 \%)$ and was higher in males than females $(\mathrm{OR}=5)$. Higher $\mathrm{BMI}$ and higher WC, both in young individuals and in the elderly, were related to worse cognitive performance. Cognitive performance across different tests was worst in obese individuals. Central obesity subtly impacts mood and motor skills. Analyses uncovered a likely mechanism for these cognitive deficits, as interleukin (IL)-9, 10, 17, 20, 23 and TNF were significantly associated with most cognitive variables. Age has a substantial impact on the relationship between cytokines and cognitive performance as most correlations became non-significant among the older individuals. The results indicate the importance of cytokines and obesity to neurocognitive status.

Keywords: HIV; Cognition; Central obesity; BMI; Waist circumference; Neurocognitive impairment; BDNF; Cytokines

\section{Introduction/Literature Review}

Obesity has been on the rise in the past decade, with approximately 78.6 million men and women in America being either overweight or obese (body mass index (BMI) $>25 \mathrm{~kg} / \mathrm{m}^{2}$ ) [1]. These rates are of great concern given obesity's well-known association with cardiovascular disease, diabetes, and hypertension all of which costs over $\$ 147$ billion U.S. dollars per year $[2,3]$.

More recently, the association between obesity and impaired neuropsychological function has been recognized [4,5]. Nevertheless, studies have been inconsistent when delineating the effects of obesity on cognitive performance in older individuals [5]. Few studies have reported a significant association between cognitive impairment and obesity. While others have found that, for some groups, being overweight may be advantageous rather than detrimental, and could even entail some survival benefits. This is known as "the obesity paradox" [6,7]. Disparities in findings are perhaps related to the fact that obese individuals (from a BMI standpoint) have different body shapes, fat distribution, and lipid profiles. Epidemiological studies examining the different phenotypes have concluded that central obesity is largely responsible for an increased risk of cardiovascular disease. Yet, whether or not central obesity is more closely related to cognition than general obesity is still debated [6,7].

Although extensively argued in the general literature, it is currently unknown if obesity provides a global advantage at any age among people living with HIV (PLWH/AIDS). Determining the relationship between obesity and cognitive status will be highly relevant, given that the negative effects of both disorders are expected to rise with the prolonged life expectancy achieved with antiretroviral therapy (ART) [8-10]. Equally important is the determination of the potential mechanisms underlying both of these disorders, because most studies done in humans lack this information [11]. While nutrition has been known to influence cognitive performance by altering key substrates and systemic energy balance, when malnutrition is absent (which is the case for most PLWH/AIDS), remarkably little is known regarding these mechanisms. Notably, people living with HIV, and particularly those with HIV associated neurological disorders, exhibited an increased inflammatory profile. However, the source of such increases in those receiving antiretroviral therapy is not fully known [12]. Given that white fat have been identified as a potential source of inflammatory signals it could be a potential mechanism whereby obesity leads to cognitive alterations. Equally important also it to establish if a central age-associated cytokine dysregulation may be impacting cognition

*Corresponding author: Maria Jose Miguez-Burbano, Professor, Florida Internationa University/School of Integrated Sciences and Humanity, AHC4 - 355, 11200 S.W. 8th St. Miami, FL 33199, USA, Tel: 561-422-3610; E-mail: mjmiguez@fiu.edu

Received June 04, 2016; Accepted June 20, 2016; Published June 27, 2016

Citation: Míguez MJ, Bueno D, Perez C, Espinoza LA, Vargas ME, et al. (2016) Obesity, Cytokines and Cognition across the Lifespan among People Living with HIV. J AIDS Clin Res 7: 593. doi:10.4172/2155-6113.1000593

Copyright: (c) 2016 Míguez MJ, et al. This is an open-access article distributed under the terms of the Creative Commons Attribution License, which permits unrestricted use, distribution, and reproduction in any medium, provided the original author and source are credited. 
because the existent literature is mostly focused in a few cytokines [12]. In addition, age-related increases in cytokines have been done using the supernatant of cultured mononuclear cells, which is the ideal method age differences in cytokines have not been demonstrated $[13,14]$.

In summary, in this population (PLWH/AIDS) at risk for cognitive disorders it is important to determine whether central or global obesity entails different risks. This can be done, for example, by modeling metabolic or immune factors. Such information could be highly valuable for planning preventative and therapeutic efforts. Therefore, the purpose of these analyses is to assess these relationships in both middle-aged and older individuals living with HIV. This information will also be relevant to public health authorities, given the association between obesity and cognitive disabilities with reduced quality of life, limitations in performing daily activities, and increased mortality risks.

We posit that: 1) obesity will be related to lower cognitive function; 2) that central adiposity is more strongly associated with lower cognitive function than global obesity, 3) that BNDF alterations are linked to both cognition and obesity; 4) that this relation is attenuated by age and 5) we will explore if systemic inflammation associated with obesity leads to cognitive impairment.

\section{Methods}

\section{Study population}

The Platelets Mediating Alcohol and HIV Damage Study (PADS) was a prospective cohort study investigating the prevalence and consequence of platelet-associated disturbances on neuro-immune comorbidities among people with HIV-1 who are hazardous alcohol users (HAU), and HIV-1 socio-demographically and clinically matched non-HAU controls. Our choice of PLWH/AIDS in an open-access public health system with standard treatment protocols was purposefully designed to minimize social, medical, and treatment inequalities. The study started in June 2010, and ended in June 2013, with a total of 400 subjects enrolled in the study.

Non-ambulatory patients, and those presenting major medical comorbidities, were excluded. Participants were questioned about several medical disorders, and research study staff reviewed medical records to confirm their eligibility. Participants with a history of central nervous system (CNS) opportunistic infection, head injury with or without loss of consciousness, tumors, major psychiatric disease, a developmental disorder, past or current bipolar disorder (as determined via medical chart review), severe malnutrition, chronic renal failure, or thyroid, cardiovascular, or immune-based diseases were ineligible. In addition, participants who had cirrhosis, active viral hepatitis, or liver enzymes two standard deviations above normal values were ineligible. To reduce the confounding effects of illicit drug use, the DSM-IV-TR questionnaire was applied, and those participants who were dependent on drugs or injecting illicit psychoactive substances were excluded [15]. The Institutional Review Boards at Florida International University and at the University of Miami approved the protocol. The study was conducted according to the principles expressed in the Declaration of Helsinki. Those participants who provided written informed consent, and signed a medical release form, were consequently enrolled and followed over a period of twelve months.

\section{Participants' assessment protocol}

At baseline we obtained sociodemographic, alcohol use, and medical history information (e.g. ART details) using computerized structured questionnaires and self-reports; this information was confirmed using available medical records, or data was amended when applicable, based on medical records. Blood was drawn in fasting subjects in order to best evaluate immunological, metabolic, and nutritional profiles. At the end, participants completed a neuropsychological assessment to ensure that they were sufficiently relaxed and comfortable with the research staff.

\section{Anthropometrics}

Basic body composition was measured by trained staff using quality assurance methods, which were tightly defined to reduce systematic errors. Body weight in kilograms was measured after an overnight fast, and height was measured to the nearest centimeter. Measured weight and height were used to calculate BMI (weight $[\mathrm{kg}] /$ height $[\mathrm{m}]^{2}$ ). Participants were classified as thin if BMI was $<18.5 \mathrm{~kg} / \mathrm{m}^{2}$, eutrophic if BMI was $18.5-24.9 \mathrm{~kg} / \mathrm{m}^{2}$, overweight if BMI was $25-29.9 \mathrm{~kg} / \mathrm{m}^{2}$, and obese if BMI was $\geq 30 \mathrm{~kg} / \mathrm{m}^{2}$.

Since BMI is a measure of overall body composition, but does not account for the wide variation in body fat distribution, we evaluated waist/hip ratio and waist circumference as indicators of visceral adiposity. Waist and hip circumferences were measured using a non-stretchable tape positioned at the high point of the iliac crest for the waist and at the greatest circumference of the buttocks. Each measurement was made with minimal respiration to the nearest 0.1 $\mathrm{cm}$ with the tape snug, but not compressing the skin. Based on the National Cholesterol Education Program, central obesity was defined as a woman with a waist larger than 35 inches and a man with a waist more than 40 inches [16].

\section{Neuropsychological assessments}

Our main outcome of interest was cognitive performance. An experienced member of the team assessed participants with a neuropsychological battery that complies with national guidelines ("Clinical confirmation of the American Academy of Neurology algorithm for HIV-1-associated cognitive motor disorder and the NIH ToolBox") [17]. Eight different neuropsychological tests were completed within the same visit, however, breaks and optimal conditions for testing (e.g. appropriate lighting, silence, and isolation from unnecessary stimuli) were provided. Intraclass correlation coefficients for the entire sample on the NIH Toolbox measures ranged from 0.78 to 0.99 , with most other values falling above 0.90 [18]. The neurocognitive test battery evaluated the following: 1) The Color Trails Test, selected to assess executive functions, and to minimize the influence of language and cultural bias [19], 2) Digital Symbol Substitution measures visuoperceptual and motor processes [20], 3) Block Design assesses visuospatial/visuo-constructive skills [21], 4) The California Verbal Learning Test (CVLT), was used to assess verbal learning and memory [22], 5) The Rey Complex Figure Test (RCFT) measures visuo-spatial functioning, retrieval and recall abilities [23] and 6) The Grooved Pegboard Test (GPT) evaluates psychomotor efficiency that requires the integration of fine motor dexterity with visual and kinesthetic information, using dominant and non-dominant hands [24].

Using the corresponding manuals, raw scores were converted into $\mathrm{T}$-scores or Z-scores, to control for the effects of age, education, gender and where available, ethnicity.

\section{Cytokines}

Since studies have proven that peripheral measures may not be the most reliable. Peripheral blood mononuclear cells were isolated and culture supernatant were collected to quantify IL-4, IL-6, TNF, IL-9, IL-12, IL-17, IL-20, IL-23 and anti-inflammatory (IFN- $\alpha$, IFN- $\beta$, IL- 
13 and IL-10) cytokines. Concentrations of these cytokines will be quantitatively determined using MILLIPLEX MAP Human Cytokine Magnetic Bead Panel from Millipore (EMD Millipore Corporation, Billerica, MA, USA). The Standard Curve Range for most of the cytokines range from $0.64-10,000 \mathrm{pg} / \mathrm{mL}$.

\section{Co-variates}

Since prior studies have postulated some factors which could account for the variability in cognitive performance, data measuring these factors were collected and included: gender socio-economic status, age, education, lipid abnormalities, hazardous alcohol consumption (NIAAA criteria: 7 drinks/week among women and 14 drinks/week for men) [25], smoking (yes/no) [26], high blood pressure (SBP $\geq 140$ $\mathrm{mmHg}$ and/or DBP $\geq 90 \mathrm{mmHg}$ : yes/no) [26], and diabetes (yes/no) [27]. HIV disease markers were also included (CD4 and HIV viral burden -Roche Diagnostic System), along with detailed information on antiretroviral medications used.

\section{Statistical analyses}

The data were analyzed using SPSS 18.0 for Windows (IBM, Inc., Chicago, IL, USA) and $\mathrm{p}$ values $<0.05$ were considered statistically significant. Although this is a prospective cohort study, we used only 6 month data for these analyses. The distributions of our primary outcomes of interest were examined with normal probability plots. Log transformations were performed with variables not normally distributed. Percentages and frequencies were used to describe categorical variables. Viral load results (RNA copies per $\mathrm{mL}$ ) were logtransformed before analysis.

To examine the effect of lipid fractions on cognitive function, we compared means for each of the corrected cognitive scores. The significance was tested by means of ANOVA and t- test for independent samples, respectively. Because demographics (i.e., age, educational level), clinical history (CD4 and viral load), and hazardous alcohol use had been found to alter cognitive functions, we assessed their possible confounding or modifying effects. Finally, any variables that were significant in these analyses were included as independent variables in the multivariate regression analyses, with the cognitive tests as dependent variables.

\section{Results}

\section{Sample characteristics}

Only $1 \%$ of the cohort was underweight. Because they were so few, these subjects were combined with non-obese subjects. Overall, onethird of the study sample had a BMI $<25 \mathrm{~kg} / \mathrm{m}^{2}$. Many participants met the definitions of overweight $\left(26 \% ; 25-29.9 \mathrm{~kg} / \mathrm{m}^{2}\right)$ and obese $(35 \% ; \geq 30$ $\left.\mathrm{kg} / \mathrm{m}^{2}\right)$. Notably, females' risk for general obesity was higher than males' $(\mathrm{OR}=5$; 95\% CI: 2.9-8.8, $\mathrm{p}=0.000)$. The mean waist circumference for females was ( $40.0 \pm 7.0$ inches) and for males ( $37.1 \pm 6.1$ inches). Central obesity was present in $52 \%$ of the study participants. Males were twice as likely to have central obesity than their female counterparts $(\mathrm{OR}=1.8$; 95\% CI: 1.2-2.7, p=0.002). Rates of obesity and central fat accumulation were similarly distributed in middle age individuals and in the elderly.

Demographic data, indices of HIV disease status, and general health for eutrophic, overweight and obese individuals are depicted in Table 1. As evident in the table, a large proportion of minorities and females were classified as overweight or obese. Groups were similar in social characteristics (i.e., education, income). As expected, obese individuals had a worse metabolic profile. Obese subjects had higher levels of triglyceride, cholesterol and glucose, compared with both the overweight and the eutrophic subjects. However, in accord with our

\begin{tabular}{|c|c|c|c|c|}
\hline Variable & Obese $(n=141)$ & Overweight (n=108) & Normal (n=148) & $P$ value \\
\hline Age & $42.6 \pm 6.4$ & $42.3 \pm 7.4$ & $42.7 \pm 6$ & 0.7 \\
\hline Men & $44 \%$ & $68 \%$ & $79 \%$ & \multirow[t]{2}{*}{0.001} \\
\hline Women & $56 \%$ & $32 \%$ & $21 \%$ & \\
\hline African American & $74 \%$ & $57 \%$ & $71 \%$ & \multirow[t]{4}{*}{0.006} \\
\hline Black Caribbean & $2 \%$ & $2 \%$ & $4 \%$ & \\
\hline Hispanic & $17 \%$ & $36 \%$ & $21 \%$ & \\
\hline White & $7 \%$ & $5 \%$ & $4 \%$ & \\
\hline $\begin{array}{l}\text { Annual Income: } \\
\text { Less than } \$ 10,000\end{array}$ & $85 \%$ & $88 \%$ & $90 \%$ & \multirow[t]{4}{*}{0.7} \\
\hline$\$ 11,000-\$ 20,000$ & $11 \%$ & $8 \%$ & $6 \%$ & \\
\hline$\$ 20,000-\$ 49,000$ & $2 \%$ & $2 \%$ & $4 \%$ & \\
\hline$>\$ 50,000$ & $2 \%$ & $2 \%$ & $0 \%$ & \\
\hline Education (years of school) & $11.5 \pm 2$ & $11.3 \pm 2.4$ & $11.3 \pm 2.6$ & 0.1 \\
\hline Albumin & $4.5 \pm 0.5$ & $4.3 \pm 0.4$ & $4.2 \pm 0.5$ & 0.1 \\
\hline Cholesterol mg/dl & $190.6 \pm 46.9$ & $181.5 \pm 38.1$ & $167.6 \pm 40.88$ & 0.045 \\
\hline Triglycerides mg/dl & $193.6 \pm 14.7$ & $149.2 \pm 13.7$ & $115.5 \pm 10.1$ & 0.031 \\
\hline Glucose mg/dl & $104.9 \pm 61.5$ & $86.6 \pm 20.1$ & $86.4 \pm 25.8$ & 0.002 \\
\hline AST & $32.5 \pm 23$ & $34.1 \pm 18$ & $34.6 \pm 16$ & 0.6 \\
\hline ALT & $37.1 \pm 33$ & $37.8 \pm 20$ & $39.2 \pm 19.9$ & 0.8 \\
\hline CD4 cell counts & $536 \pm 309$ & $406.6 \pm 270$ & $383.9 \pm 251$ & 0.001 \\
\hline Viral Load Log & $2.5 \pm 1.3$ & $2.6 \pm 1.3$ & $2.8 \pm 1.2$ & 0.04 \\
\hline Platelets & $258.5 \pm 137.9$ & $217.8 \pm 85$ & $220.7 \pm 76.0$ & 0.02 \\
\hline Framingham Score & $5.0 \pm 4.3$ & $4.3 \pm 3.5$ & $4.6 \pm 4.4$ & 0.55 \\
\hline
\end{tabular}

Note: Demographic characteristics were expressed as percentages by BMI group. Biological measures were presented as means and standard deviations Note: AST=Aspartate Transaminase also called Glutamic Oxaloacetic Transaminase (SGOT) and ALT=Alanine Aminotransferase also called Glutamic Pyruvic Transaminase (SGPT)

Table 1: Sociodemographic and clinical characteristics of HIV infected patients by BMI. 
prior studies [28], obese individuals exhibited a better HIV profile, as indicated by higher CD4 cell counts and lower viral burdens.

\section{Cognitive performance, body mass index, and waist circumference}

As a first step, we explored the correlations between BMI, waist circumference, and central obesity with the different cognitive domains. Notably, several significant associations between BMI at baseline and several of the cognitive domains were observed. As depicted in Table 2, cognitive performance was more frequently correlated with central obesity. Global dementia was associated with measurements of being overweight/obese (BMI, waist circumference and the dichotomous variable [ $<35$ females and $>40$ males]). All body measurements were also correlated with performance on the Color Trail Test. Yet, the total score of the California Verbal Learning Test and the Visual Ray Tests were mostly associated with waist circumference measurements.

\begin{tabular}{|c|c|c|c|c|}
\hline Variable & & Waist & High Waist & BMI \\
\hline HIV Dementia & $\begin{array}{c}\text { Correlation } \\
\mathrm{P} \text { value }\end{array}$ & $\begin{array}{l}0.179^{* *} \\
0.001\end{array}$ & $\begin{array}{c}-0.212^{* *} \\
0.000\end{array}$ & $\begin{array}{l}223^{* *} \\
0.000\end{array}$ \\
\hline Color Trail 2 & $\begin{array}{l}\text { Correlation } \\
\mathrm{P} \text { value }\end{array}$ & $\begin{array}{l}0.134^{*} \\
0.032\end{array}$ & $\begin{array}{c}-0.245^{* *} \\
0.000\end{array}$ & $\begin{array}{l}0.136 \\
0.029\end{array}$ \\
\hline $\begin{array}{l}\text { Time Dominant Hand } \\
\text { Non-Dominant Hand }\end{array}$ & $\begin{array}{c}\text { Correlation } \\
\text { P value } \\
\text { Correlation } \\
\text { P value }\end{array}$ & $\begin{array}{l}0.080 \\
0.130 \\
0.053 \\
0.320\end{array}$ & $\begin{array}{c}-0.056 \\
0.286 \\
-0.086 \\
0.103\end{array}$ & $\begin{array}{l}0.098 \\
0.064 \\
0.080 \\
0.132\end{array}$ \\
\hline Visual recall & $\begin{array}{r}\text { Correlation } \\
\mathrm{P} \text { value }\end{array}$ & $\begin{array}{l}0.154^{* *} \\
0.003\end{array}$ & $\begin{array}{l}-0.058 \\
0.269\end{array}$ & $\begin{array}{l}0.128 \\
0.015\end{array}$ \\
\hline Verbal Learning & $\begin{array}{c}\text { Correlation } \\
\mathbf{P} \text { value }\end{array}$ & $\begin{array}{l}0.133^{*} \\
0.012\end{array}$ & $\begin{array}{c}-0.046 \\
0.386\end{array}$ & $\begin{array}{l}0.056 \\
0.295\end{array}$ \\
\hline Block Design Scale & $\begin{array}{r}\text { Correlation } \\
\text { P value }\end{array}$ & $\begin{array}{l}0.025 \\
0.646\end{array}$ & $\begin{array}{l}0.058 \\
0.283\end{array}$ & $\begin{array}{l}0.013 \\
0.806\end{array}$ \\
\hline Digit Symbol Scale & $\begin{array}{r}\text { Correlation } \\
\mathbf{P} \text { value }\end{array}$ & $\begin{array}{l}0.076 \\
0.159\end{array}$ & $\begin{array}{l}-0.117^{*} \\
0.029\end{array}$ & $\begin{array}{l}0.086 \\
0.111\end{array}$ \\
\hline Symbol Search Scale & $\begin{array}{l}\text { Correlation } \\
\mathbf{P} \text { value }\end{array}$ & $\begin{array}{l}0.005 \\
0.931\end{array}$ & $\begin{array}{c}-0.073 \\
0.168\end{array}$ & $\begin{array}{l}0.009 \\
0.871\end{array}$ \\
\hline Coding Scale & $\begin{array}{l}\text { Correlation } \\
\mathrm{P} \text { value }\end{array}$ & $\begin{array}{l}-0.019 \\
0.720\end{array}$ & $\begin{array}{c}-0.021 \\
0.689\end{array}$ & $\begin{array}{l}0.042 \\
0.434\end{array}$ \\
\hline WCST Number of Trials & $\begin{array}{l}\text { Correlation } \\
\mathrm{P} \text { value }\end{array}$ & $\begin{array}{c}-0.014 \\
0.790\end{array}$ & $\begin{array}{l}0.041 \\
0.431\end{array}$ & $\begin{array}{r}-0.021 \\
0.694\end{array}$ \\
\hline WCST Correct & $\begin{array}{l}\text { Correlation } \\
\mathbf{P} \text { value }\end{array}$ & $\begin{array}{l}0.069 \\
0.188\end{array}$ & $\begin{array}{c}-0.079 \\
0.134\end{array}$ & $\begin{array}{l}0.092 \\
0.081\end{array}$ \\
\hline
\end{tabular}

Values represent standardized scores

Table 2: Correlations between anthropometrics and cognitive performance.
Table 3 shows the test scores according to BMI and age groups. The dementia scores for middle age obese individuals were significantly higher than the mean of any other group, suggesting a risk for obese PLWH/AIDS. Obese individuals also had higher Color Trail T scores. Obese individuals also had worse scores on other motor tests, such as the Pegboard, particularly as they aged. As depicted in Table 3, the average time to complete the task with the dominant hand was 6 seconds higher in older obese individuals than their matching counterparts. Nonetheless, a tendency was observed for obese individuals to perform slightly better on the Digit symbol test. Notably, overweight people also exhibited poor performancesin the same areas, yet difficulties were less marked.

Additional analyses of the different domains indicated that in addition to the global damage observed in obese individuals, memory domains were not compromised. For example, there were no differences in scores in the visual recalls or in the California Verbal Learning Test.

\section{Central obesity}

As depicted in Table 4, middle age adults with central obesity scored poorly on the HIV dementia and the Color Trail tests. Yet, we did not identify differences in other tests assessing executive functioning.

Mean performance on Grooved Pegboard Test was lower in the groups with central obesity, yet it only achieved statistical significance in the middle age group. Among them, the time to complete the task with the non-dominant hand was significantly longer in older obese adults than in their leaner counterparts $(100.2 \pm 42$ vs. $89.2 \pm 22.8$, $p=0.02$ ).

\section{Obesity in relationship to cytokines}

Only levels of IL- 6 and TNF were higher in the obese individuals compared with their lean counterparts $(844.9 \pm 314.2$ vs. $387.5 \pm 73.3$ $\mathrm{pg} / \mathrm{mL}, \mathrm{p}=0.01)$, TNF (Obese $=3.1 \pm 0.39$ vs $2.02 \pm 0.12 \mathrm{pg} / \mathrm{mL}, \mathrm{p}=0.02$ respectively). The IL-23 mean levels were $34.99 \pm 4.9 \mathrm{pg} / \mathrm{ml}$ in the subjects with central obesity, which was significantly higher compared with the concentration of $20.6 \mathrm{pg} / \mathrm{ml}$ in the HDs $(\mathrm{P}<0.008)$. IL-9 was also elevated $(914.9 \pm 264.9$ vs. $197.5 \pm 183.4 \mathrm{pg} / \mathrm{ml} \mathrm{p}=0.028)$.

Interestingly, an age dependent effect in IL-20 was identified. It was significantly lower among middle age obese individuals ( $28 \pm 22$ vs. 66 $\pm 27 \mathrm{pg} / \mathrm{mL}, \mathrm{p}=0.03$ ), however, a tendency of higher levels was observed in older individuals with ( $26 \pm 8$ vs. $13 \pm 4 \mathrm{pg} / \mathrm{mL}, \mathrm{p}=0.09)$.

\begin{tabular}{|c|c|c|c|c|c|c|}
\hline \multirow[b]{2}{*}{ Variable } & \multicolumn{3}{|c|}{ Middle Age $(n=340)$} & \multicolumn{3}{|c|}{ Older Individuals $(>50, n=60)$} \\
\hline & $\mathrm{BMI}<25$ & $\mathrm{BMI}>25$ & Pvalue & $\mathrm{BMI}<25$ & $\mathrm{BM} \mid>25$ & $P$ value \\
\hline Beck Depression & $16.57 \pm 11.38$ & $17.25 \pm 12.34$ & 0.620 & $18.00 \pm 12.9$ & $16.72 \pm 10.9$ & 0.69 \\
\hline HIV Dementia & $6.02 \pm 3.11$ & $7.17 \pm 2.91$ & 0.001 & $6.34 \pm 2.87$ & $6.81 \pm 2.85$ & 0.45 \\
\hline Color Trail 2 T score & $45.42 \pm 13.07$ & $47.44 \pm 11.64$ & 0.225 & $48.87 \pm 13.27$ & $46.54 \pm 12.7$ & 0.58 \\
\hline $\begin{array}{l}\text { Time Dominant Hand } \\
\text { Time Non-Dominant Hand }\end{array}$ & $\begin{array}{l}80.06 \pm 25.10 \\
92.72 \pm 37.87\end{array}$ & $\begin{array}{c}84.64 \pm 33.7 \\
94.23 \pm 36.14\end{array}$ & $\begin{array}{l}0.166 \\
0.724\end{array}$ & $\begin{array}{l}88.92 \pm 29.82 \\
92.62 \pm 45.47\end{array}$ & $\begin{array}{c}92.34 \pm 18.0 \\
107.41 \pm 27.9\end{array}$ & $\begin{array}{l}0.75 \\
0.13\end{array}$ \\
\hline Visual Recall & $4.67 \pm 1.84$ & $4.71 \pm 1.600$ & 0.822 & $4.92 \pm 1.61$ & $4.68 \pm 1.80$ & 0.59 \\
\hline Verbal Learning T1-T5 & $36.03 \pm 10.25$ & $37.08 \pm 8.92$ & 0.354 & $34.9 \pm 8.09$ & $37.03 \pm 8.73$ & 0.21 \\
\hline Block Design Scale & $5.47 \pm 1.91$ & $5.55 \pm 2.36$ & 0.727 & $6.13 \pm 2.01$ & $5.58 \pm 1.81$ & 0.29 \\
\hline Digit Symbol Scale & $6.54 \pm 2.18$ & $7.08 \pm 2.91$ & 0.067 & $7.39 \pm 2.85$ & $7.15 \pm 2.63$ & 0.73 \\
\hline Symbol Search Scale & $7.77 \pm 2.71$ & $7.85 \pm 2.85$ & 0.789 & $8.22 \pm 2.86$ & $7.58 \pm 2.85$ & 0.41 \\
\hline Coding Scale & $6.14 \pm 2.36$ & $6.74 \pm 3.78$ & 0.083 & $6.52 \pm 2.33$ & $6.33 \pm 2.94$ & 0.79 \\
\hline WCST Number of Trials & $121.4 \pm 14.02$ & $121.07 \pm 14.95$ & 0.821 & $125.0 \pm 10.74$ & $122.06 \pm 4.35$ & 0.37 \\
\hline WCST Correct & $63.78 \pm 18.98$ & $67.78 \pm 17.20$ & 0.108 & $68.13 \pm 14.41$ & $69.94 \pm 17.03$ & 0.66 \\
\hline
\end{tabular}

Note: Values represent standardized scores 
Page 5 of 7

\begin{tabular}{|l|c|c|c|c|c|c|}
\hline & \multicolumn{2}{|c|}{ Middle Age } & & \multicolumn{2}{c|}{ Older Age } \\
\hline Variable & $\begin{array}{c}\text { Normal Waist } \\
\mathbf{N = 1 4 8}\end{array}$ & $\begin{array}{c}\text { Central Obesity } \\
\mathbf{N = 1 8 2}\end{array}$ & P value & Normal waist & Central Obesity & P value \\
\hline Beck Depression & $16.8 \pm 12.3$ & $16.9 \pm 12.1$ & 0.88 & $19.3 \pm 14.7$ & $16.2 \pm 10.8$ & 0.40 \\
\hline Stress Score & $12.7 \pm 10.8$ & $8.8 \pm 10.2$ & 0.001 & $10.41 \pm 10.3$ & $13.3 \pm 9.88$ & 0.31 \\
\hline HIV Dementia & $6.21 \pm 3.1$ & $7.3 \pm 2.85$ & 0.050 & $5.57 \pm 2.70$ & $7.2 \pm 2.76$ & 0.03 \\
\hline Color Trail 2 T score & $49.9 \pm 10.0$ & $43.66 \pm 13.6$ & 0.000 & $44.26 \pm 14.45$ & $49.4 \pm 11.59$ & 0.26 \\
\hline Time Dominant Hand & $81.3 \pm 24.9$ & $88.5 \pm 37.1$ & 0.049 & $92.76 \pm 30.97$ & $96.0 \pm 41.25$ & 0.73 \\
\hline Time Non-Dominant Hand & $89.2 \pm 22.8$ & $100.2 \pm 42.3$ & 0.025 & $89.43 \pm 32.29$ & $107.5 \pm 40.71$ \\
\hline Visual recall & $4.8 \pm 1.5$ & $4.49 \pm 1.8$ & 0.075 & $4.38 \pm 1.77$ & $4.9 \pm 1.7$ & 0.07 \\
\hline California Verbal Learning T1-T5 & $37.1 \pm 9.7$ & $36.21 \pm 9.7$ & 0.405 & $35.14 \pm 8.55$ & $36.0 \pm 8.1$ & 0.26 \\
\hline Block Design Scale & $5.35 \pm 2.23$ & $5.65 \pm 2.2$ & 0.257 & $5.75 \pm 1.55$ & $5.67 \pm 2.23$ & 0.88 \\
\hline Digit Symbol Scale & $7.13 \pm 2.49$ & $6.4 \pm 2.9$ & 0.474 & $7.15 \pm 2.79$ & $7.33 \pm 2.43$ & 0.81 \\
\hline Symbol Search Scale & $7.9 \pm 2.7$ & $7.7 \pm 3.1$ & 0.908 & $7.40 \pm 2.58$ & $8.06 \pm 2.98$ & 0.39 \\
\hline Coding Scale & $6.6 \pm 2.45$ & $6.51 \pm 4.4$ & 0.915 & $5.95 \pm 2.18$ & $6.67 \pm 2.97$ & 0.30 \\
\hline
\end{tabular}

Table 4: Cognitive performance by central obesity and age groups.

\begin{tabular}{|c|c|c|c|c|c|c|}
\hline Variable & TNF & IL-9 & IL-13 & IL-20 & IL-23 & IL-17 \\
\hline $\begin{array}{c}\text { California Verbal Learning } \\
\text { Correlation } \\
\text { P value }\end{array}$ & $\begin{array}{l}0.025 \\
0.646\end{array}$ & $\begin{array}{l}0.058 \\
0.283\end{array}$ & $\begin{array}{r}-0.057 \\
0.602\end{array}$ & $\begin{array}{l}0.232 \\
0.031\end{array}$ & $\begin{array}{l}-0.274 \\
0.008\end{array}$ & $\begin{array}{l}0.013 \\
0.806\end{array}$ \\
\hline $\begin{array}{l}\text { Digit Symbol Scale } \\
\text { Correlation }\end{array}$ & $\begin{array}{l}0.076 \\
0.159\end{array}$ & $\begin{array}{c}-0.117 \\
0.029\end{array}$ & $\begin{array}{c}-0.164 \\
0.135\end{array}$ & $\begin{array}{c}-0.106 \\
0.300\end{array}$ & $\begin{array}{l}-0.278 \\
0.007\end{array}$ & $\begin{array}{l}0.086 \\
0.111\end{array}$ \\
\hline $\begin{array}{l}\text { Visual Recall } \\
\text { Correlation }\end{array}$ & $\begin{array}{l}0.013 \\
0.833\end{array}$ & $\begin{array}{c}-0.169 \\
0.09\end{array}$ & $\begin{array}{c}-00.88 \\
0.423\end{array}$ & $\begin{array}{l}0.746 \\
0.003\end{array}$ & $\begin{array}{c}-0.204 \\
0.05\end{array}$ & $\begin{array}{l}-0.10 \\
0.092\end{array}$ \\
\hline $\begin{array}{l}\text { WCST Number of Trials } \\
\text { Correlation } \\
\end{array}$ & $\begin{array}{l}0.027 \\
0.639\end{array}$ & $\begin{array}{c}0.167 \\
0.09\end{array}$ & $\begin{array}{l}0.084 \\
0.409\end{array}$ & $\begin{array}{c}-0.196 \\
0.051\end{array}$ & $\begin{array}{c}-0.072 \\
0.51\end{array}$ & $\begin{array}{l}0.21 \\
0.04\end{array}$ \\
\hline $\begin{array}{l}\text { WCST Errors } \\
\text { Correlation }\end{array}$ & $\begin{array}{l}0.014 \\
0.808\end{array}$ & $\begin{array}{l}0.09 \\
0.32\end{array}$ & $\begin{array}{l}0.248 \\
0.021\end{array}$ & $\begin{array}{c}0.206 \\
0.05\end{array}$ & $\begin{array}{c}-0.003 \\
0.74\end{array}$ & $\begin{array}{c}0.193 \\
0.05\end{array}$ \\
\hline $\begin{array}{l}\text { HIV Dementia } \\
\text { Correlation }\end{array}$ & $\begin{array}{c}-0.187 \\
0.05\end{array}$ & 0.130 & $\begin{array}{c}-0.062 \\
0.568\end{array}$ & $\begin{array}{c}-0.190 \\
0.05\end{array}$ & $\begin{array}{c}-0.105 \\
0.221\end{array}$ & $\begin{array}{l}0.075 \\
0.461\end{array}$ \\
\hline
\end{tabular}

Note: Values represent standardized scores

Table 5: Cytokines and cognitive tests in middle age adults.

\section{Cytokines and cognitive performance}

We started by using continuous variables to identify associations between cytokine levels and global T scores in PLWH/AIDS. Table 5 presents the statistically significant correlations between cognitive tests and levels of cytokines. Correlation coefficients were in the moderate range, justifying further analyses of TNF, IL-9, and IL-17 on cognitive performance.

\section{Regression analyses}

We used a series of regression models to further identify which cytokine(s) and obesity measures were most relevant in predicting the cognitive domains most commonly affected in our sample. In all of the models we included socio-demographics, CD4, viral load, antiretroviral therapy, Framingham, lipids, glucose, ART and all cytokines as independent variables.

In the first model, analyses demonstrated that inflammatory cytokines IL-9, IL-23 and TNF influence learning and memory. Central obesity was also a significant predictor of verbal memory. Memory was also found to be sensitive to the effects of age and gender (see Table 6A).

The second regression analyses (Table 6B), with a measure of global cognition as the dependent variable, yielded a multiple R-squared of $0.43(\mathrm{p}<0.0001)$. IL-10 and IL-9, along with general obesity and glucose were the only variables explaining variance in HIV Dementia Scale scores.

The last model predicting motor function showed that BMI, an index of global obesity, was the only variable retained in statistical models. None of the cytokines and HIV clinical markers were significant in the statistical model (see Table 6C).

\section{Discussion}

First, our study showed that being overweight or obese is common (61\% of our sample) in our urban HIV population in South Florida, suggesting that we should redirect our concerns to assure that PLWH/ AIDS are maintaining a healthy, normal body weight. Analyses demonstrated that a large proportion of minorities and females were classified as overweight or obese. Our data confirms that central obesity is associated with impaired verbal and auditory working memory, and reduced capacity for decision-making. These cognitive functions are associated with the higher-order thinking required to conduct safer sex practices and health management behaviors, such as ART adherence [29]. There are now many associations that may link increased obesity to changes in cognitive performance; however the mechanisms remain highly speculative. Analyses indicated that obesity is a risk factor for cognitive declines, possibly due to white fat inducing an inflammatory response that could directly or indirectly alter cognitive function 
Citation: Míguez MJ, Bueno D, Perez C, Espinoza LA, Vargas ME, et al. (2016) Obesity, Cytokines and Cognition across the Lifespan among People Living with HIV. J AIDS Clin Res 7: 593. doi:10.4172/2155-6113.1000593

Page 6 of 7

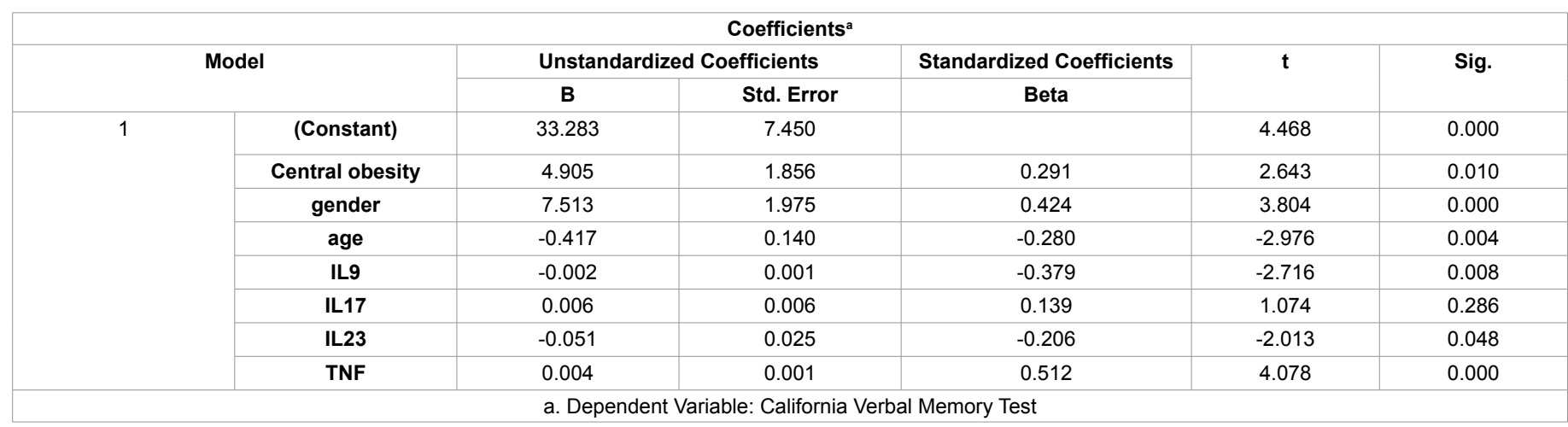

Table 6A: Predictors of verbal memory.

\begin{tabular}{|c|c|c|c|c|c|c|}
\hline \multicolumn{7}{|c|}{ Coefficients $^{a}$} \\
\hline \multicolumn{2}{|c|}{ Model } & \multicolumn{2}{|c|}{ Unstandardized Coefficients } & \multirow{3}{*}{$\begin{array}{c}\text { Standardized Coefficients } \\
\text { Beta }\end{array}$} & \multirow{3}{*}{$\begin{array}{c}\mathbf{t} \\
0.671\end{array}$} & \multirow{3}{*}{$\begin{array}{l}\text { Sig. } \\
0.504\end{array}$} \\
\hline & & \multirow{2}{*}{$\frac{\text { B }}{1.914}$} & \multirow{2}{*}{$\begin{array}{c}\text { Std. Error } \\
2.854\end{array}$} & & & \\
\hline 1 & (Constant) & & & & & \\
\hline & Education & 0.474 & 0.126 & 0.407 & 3.759 & 0.000 \\
\hline & Income & -0.885 & 0.634 & -0.141 & -1.396 & 0.167 \\
\hline & Age & -0.065 & 0.051 & -0.128 & -1.267 & 0.209 \\
\hline & Gender & 2.792 & 0.596 & 0.490 & 4.688 & 0.000 \\
\hline & BMI & -0.080 & 0.040 & -0.211 & -2.014 & 0.048 \\
\hline & Glucose & 0.025 & 0.008 & 0.358 & 3.002 & 0.004 \\
\hline & Interl6 & 0.001 & 0.000 & 0.220 & 1.559 & 0.123 \\
\hline & IL-9 & 0.000 & 0.000 & 0.226 & 2.323 & 0.023 \\
\hline & IL-10 & -0.003 & 0.001 & -0.377 & -2.431 & 0.017 \\
\hline
\end{tabular}

Table 6B. Predictors of global cognitive function.

\begin{tabular}{|c|c|c|c|c|c|c|}
\hline \multicolumn{7}{|c|}{ Coefficients $^{a}$} \\
\hline \multicolumn{2}{|c|}{ Model } & \multicolumn{2}{|c|}{ Unstandardized Coefficients } & \multirow{2}{*}{$\begin{array}{c}\text { Standardized Coefficients } \\
\text { Beta }\end{array}$} & \multirow[t]{2}{*}{$\mathbf{t}$} & \multirow[t]{2}{*}{ Sig. } \\
\hline & & B & Std. Error & & & \\
\hline \multirow[t]{7}{*}{1} & (Constant) & 96.091 & 13.204 & & 7.278 & 0.000 \\
\hline & $\mathrm{BMI}$ & -3.060 & 0.913 & -0.332 & -3.353 & 0.001 \\
\hline & education & 0.578 & 0.308 & 0.185 & 1.879 & 0.063 \\
\hline & IL12 & 0.112 & 0.098 & 0.116 & 1.145 & 0.255 \\
\hline & IL20 & -0.096 & 0.084 & -0.112 & -1.143 & 0.256 \\
\hline & CD4 & 0.002 & 0.007 & 0.037 & 0.356 & 0.723 \\
\hline & VIRAL LOAD & $5.552 E-006$ & 0.000 & 0.033 & 0.329 & 0.743 \\
\hline
\end{tabular}

Table 6C: Predictors of motor function.

[30,31]. The importance of understanding the risks and benefits of increased weight in aging and its related diseases are critical for providing the most basic lifestyle advice and support to our growing aging communities.

So, what can explain the association between body-changes with cognitive performance? First, it needs to be noted that fat is no longer considered an inert bystander, rather studies have demonstrated that fat is an active endocrine organ able to activate a pro-inflammatory network [30,31]. Our analyses demonstrated the classical increase on IL-6 and TNF associated with cognitive impairment. These results extend prior work in this area by demonstrating that both obesity and cognitive performance were associated with changes on IL-9, IL-17 and IL-23. These findings, while new, are in line with the mounting evidence that neuro-inflammation fans HIV associated neurological pathology [32]. While many studies focused on assessing cytokines in cerebrospinal fluid, our data highlight the relevance of systemic inflammation. These cytokines can exert their action by crossing the blood-brain barrier directly via active transport mechanisms. Chronic inflammation can also lead to microglial infiltration and activation of factor NFkB [30-33]. The final result, according to preclinical models, is synaptic remodeling, neuronal apoptosis, and impaired neurogenesis. This suggests that blocking relevant cytokine pathways could slow disease development.

In addition to inflammatory changes, the data also points to the likely contribution of metabolic alterations on cognitive impairment. Integrative components of metabolic syndrome, such as lipids and glucose, can be contributing to the problem. Analyses also highlight the importance of obtaining measures of central obesity, as it may provide distinctive information. While verbal memory was associated with central obesity, global dementia and motor skills were associated with measurements of being overweight/obese. Nonetheless, analyses showed that cognitive performance was more frequently correlated 
Citation: Míguez MJ, Bueno D, Perez C, Espinoza LA, Vargas ME, et al. (2016) Obesity, Cytokines and Cognition across the Lifespan among People Living with HIV. J AIDS Clin Res 7: 593. doi:10.4172/2155-6113.1000593

with central obesity. Unfortunately, waist, hip, and abdominal circumferences are not commonly measured.

Though it has been suggested that the performance differences between obese and non-obese adults is restricted to executive tasks, our findings show motor alterations in tests like the pegboard. Specifically, completing the task with the non-dominant hand took significantly longer in older obese adults than in their leaner counterparts. Findings are of concern because motor dexterity can affect daily living functions [34].

Nonetheless, it needs to be noted that correlations were limited and not too strong. Conclusions can be drawn with reservedly, as the study population was limited to those with HIV in clinical settings in South Florida.

In summary, our analyses suggest that in this era where antiretroviral therapy is common, obesity adds not only to systemic inflammation, but also to the risk of cognitive decay, over and above the contribution of clinical HIV markers. Since poor cognitive performance is predictive of subsequent dementia, screening obese individuals for cognitive impairments should be a cost effective measure. Additional studies are necessary to confirm whether or not these findings may extend to the general population. Such analyses are pertinent from the public health point of view given the aging of the population and the increased proportion of individuals in this country suffering from obesity. Thus, new treatments to mitigate cognitive disorders (such as those associated with HIV) must reflect on its multifactorial pathogenesis, including obesity that contributes to the inflammatory response.

\section{References}

1. Ogden CL, Carroll MD, Kit BK, Flegal KM (2014) Prevalence of childhood and adult obesity in the United States, 2011-2012. JAMA 311: 806-814.

2. O'Grady MJ, Capretta JC (2012) Assesing the economics of obesity and obesity interventions. Campaign to End Obesity.

3. Sowers JR (2003) Obesity as a cardiovascular risk factor. Am J Med 115 Suppl $8 \mathrm{~A}: 37 \mathrm{~S}-41 \mathrm{~S}$.

4. Nilsson LG, Nilsson E (2009) Overweight and cognition. Scand J Psychol 50: 660-667.

5. Chan JS, Yan JH, Payne VG (2013) The impact of obesity and exercise on cognitive aging. Front Aging Neurosci 5: 97.

6. Auyeung TW, Lee JSW, Leung J, Kwok T, Leung PC, et al. (2010) Survival in older men may benefit from being slightly overweight and centrally obese - A 5 year follow-up study in 4,000 older adults using DXA. The Journals of Gerontology Series A: Biological Sciences and Medical Sciences 65A: 99-104.

7. Hiner V, Aldhoon-Hainerova I (2013) Obesity paradox does exist. Diabetes Care 36: S276-S281

8. Fitzpatrick AL, Kuller LH, Lopez OL, Diehr P, O'Meara ES, et al. (2009) Midlife and late-life obesity and the risk of dementia: Cardiovascular health study. Arch Neurol 66: 336-342.

9. Gustafson D, Rothenberg E, Blennow K, Steen B, Skoog I (2003) An 18 year follow-up of overweight and risk of Alzheimer disease. Arch Intern Med 163: 1524-1528.

10. Stewart R, Masaki K, Xue QL, Peila R, Petrovitch H, et al. (2005) A 32 year prospective study of change in body weight and incident dementia: the Honolulu-Asia Aging Study. Arch Neurol 62: 55-60.

11. Nguyen JC, Killcross AS, Jenkins TA (2014) Obesity and cognitive decline: Role of inflammation and vascular changes. Front Neurosci 8: 375.

12. Nasi M, Pinti M, De Biasi S, Gibellini L, Ferraro D, et al. (2014) Aging with HIV infection: A journey to the center of inflammAIDS, immunosenescence and neuroHIV. Immunol Lett 162: 329-333.

13. Peterson PK, Chao CC, Carson P, Hu S, Nichol K, et al. (1994) Levels of tumor necrosis factor alpha, Interleukin-6, interleukin-10, and transforming growth factor beta are normal in the serum of the healthy elderly. Clinical Infectious Diseases 19: 1158-1159.
14. Hasegawa Y, Sawada M, Ozaki N, Inagaki T, Suzumura A (2000) Increased soluble tumor necrosis factor receptor levels in the serum of elderly people. Gerontology 46: 185-188.

15. Allen JP, Columbus M (1995) Alcohol consumption measures. Assessing alcohol problems: A guide for clinicians and researchers. Bethesda, MD pp 7595.

16. National Cholesterol Education Program (2002) Third report of the expert pane of detection, evaluation and treatment of high blood cholesterol in adults (ATP III Final Report). American Heart Association Circulation 106: 3143-3421.

17. (1996) Clinical confirmation of the American Academy of Neurology algorithm for HIV-1-associated cognitive/motor disorder. The Dana Consortium on Therapy for HIV Dementia and Related Cognitive Disorders. American Academy of Neurology 47: 1247-1253.

18. Weintraub S, Dikmen SS, Heaton RK, Tulsky DS, Zelazo PD, et al. (2013) Cognition assessment using the NIH Toolbox. Neurology 80: S54-64.

19. D'Elia L, Satz P, Uchiyama C, White T (1996) Color trails test (CTT) Psychological assessment resources, Inc., USA.

20. Bettcher BM, Libon DJ, Kaplan E, Swenson R, Penney DL (2011) "Digit Symbo substitution test." Encyclopedia of Clinical Neuropsychology. Springer New York, 849-853

21. Kohs SC (1920) The block design tests. Journal of Experimental Psychology 3: $357-376$.

22. Delis DC, Kramer JH, Kaplan E, Ober BA (2000) California verbal learning test: Second Edition. Psychological Corporation, San Antonio, TX.

23. Meyers JE, Meyers KR (1995) Rey complex figure test and recognition trial Professional manual. Psychological Assessment Resources, Lutz, FL.

24. Trites R (1989) Grooved pegboard test. Lafayette Instrument Company. Lafayette, IN.

25. Brandt J, Butters N, Ryan C, Bayog R (1983) Cognitive loss and recovery in long-term alcohol abusers. Archives of General Psychiatry 40: 435-442.

26. Ernst M, Heishman S, Spurgeon L, London E (2001) Smoking history and nicotine effects on cognitive performance. Neuropsychopharmacology 25: 313319

27. Seidell JC (2000) Obesity, insulin resistance and diabetes--a worldwide epidemic. Br J Nutr 83 Suppl 1: S5-8.

28. Shor-Posner G, Campa A, Zhang G, Persaud N, Miguez-Burbano MJ, et al (2000) When obesity is desirable: A longitudinal study of the Miamia HIV-1 infected drug abusers (MIDAS) cohort. Journal of Acquired Immune Deficiency Syndrome 23: 81-88.

29. Attonito, JM, Dévieux JG, Lerner BDG, Hospital MM, Rosenberg R (2014) Exploring substance use and HIV treatment factors associated with neurocognitive impairment among people living with HIVIAIDS. Frontiers in Public Health 2: 105

30. Bastard JP, Maachi M, Lagathu C, Kim MJ, Caron M, et al. (2006) Recent advances in the relationship between obesity, inflammation and insulin resistance. Eur Cytokine Netw 17: 4-12.

31. Coelho M, Oliveira T, Fernandes R (2013) Biochemistry of adipose tissue: An endocrine organ. Arch Med Sci 9: 191-200.

32. Zhou L, Saksena NK (2013) HIV Associated neurocognitive disorders. Infect Dis Rep 5: e8.

33. Hong S, Banks WA (2015) Role of the immune system in HIV-associated neuroinflammation and neurocognitive implications. Brain Behav Immun 45: $1-12$.

34. Wang C, Chan JS, Ren L, Yan JH (2016) Obesity reduces cognitive and motor functions across the lifespan. Neural Plast 2016: 2473081. 